\title{
Plug-in hybrid electric vehicles in the smart grid environment: an economic model of load management by demand response
}

\author{
R.Poudineh ${ }^{1}$ \\ Department of Economics, Heriot-Watt University, Edinburgh, UK
}

\begin{abstract}
Environmental concern regarding the consumption of fossil fuels is among the most serious challenges facing the world. As a result, utilisation of more renewable resources and promotion of a clean transport system such as the use of Plug in Hybrid Electric Vehicles (PHEVs) became the forefront of the new energy policies. However, the breakthrough of PHEVs in the automotive fleet increases concerns around the stability of power system and in particular, the power network. This research simulates the aggregate load profile of the UK with presence of PHEVs based upon different price scenarios. The results show that under the fixed rate and time of use programmes in the current grid, the extra load of the electric vehicles intensifies the consumption profile and also creates new critical points. Thus, there should always be excess standby capacity to satisfy peak demand even for a short period of time. On the other hand, when the consumers do not pay the price based on the actual cost of supply, those who consume less in peak hours subsidise the ones who consume more and this cross subsidy raises a regulatory issue. On the contrary, a smart grid can accommodate PHEVs without creating technical and regulatory problems. This positive consequence is the result of demand response to the real time pricing. From a technical point of view, the biggest chunk of PHEVs' load will be shifted to the late evening and the hours of minimum demand. Besides, from a welfare analysis standpoint, real time pricing creates no deadweight losses and corresponding demand response will limit the ability of suppliers to increase the spot market clearing price above its equilibrium level.
\end{abstract}

\footnotetext{
${ }^{1}$ Rp128@hw.ac.uk

The author acknowledges financial support from Scottish Institute for Research in Economics (SIRE).
} 


\section{Introduction}

Development and adoption of sustainable energy sources poses a great challenge in the world. The EU is working towards a global agreement to reduce the greenhouse gases emission and is adopting the actions of its own. In a landmark decision in December 2008, European leaders agreed on a comprehensive package of emission cutting measures [1]. The plan aims to reduce greenhouse gases by at least $20 \%$ by 2020 relative to 1990 levels, raise the share of renewable energies and reduce the overall energy consumption compared to the projected trends. At the same time the power industry and transportation sector-which account for $40 \%$ and $24 \%$ of global CO2 emissions respectively [2] have become the focal points of policies to reduce fossil fuel dependencies.

Advances in electric car technology, such as the emergence of Hybrid Electric Vehicles (HEVs), have brought innovation to an era where vehicles have been traditionally powered by gasoline. The key feature of hybrid technology is the augmentation of the engine with an electric motor, ultimately achieving improved fuel efficiency and significantly reducing the amount of $\mathrm{CO} 2$ produced by burning fossil fuels. In the case of Plug in Hybrid Electric Vehicles (PHEVs), which can be connected directly to the power grid, the impact is higher and reduction of $\mathrm{CO} 2$ emissions depends on the source of electricity generation. Therefore, in the near future a breakthrough of PHEVs in the market can be expected.

PHEVs' batteries are used steadily while driving in order to maximize fuel efficiency which causes the battery charge to decrease over time. The Vehicle thus needs to be connected to the power grid to charge its batteries when it is not in use. During its charging time, the plug-in vehicle more than doubles the average household load [3]. On the other hand, the existing distribution network is not designed for such an extra load from plug-in vehicles. Hence, a major concern is the possible impact of high load on the grid because PHEVs can plug- in for charging at any point in the distribution network regardless of the time in the day. PHEVs will imply a new load on the primary and secondary distribution networks many of which are already being operated at their maximum capacity. With the increase in the number of PHEVs, the additional load has the potential to disrupt the grid stability and significantly affect the power system dynamics as a whole.

\section{PHEVs and power system}

It has been argued that for quite some time the impact of PHEVs on the grid has been ignored [4]. It might be due to the assumption of enough power in the system or gradual penetration of the electric vehicles which provides enough time for the power system to adjust. However, since the environmental regulation enforcement becomes more stringent, this might no longer be the case. Previous studies into this issue have identified some of the consequences. For example, the impact of charging PHEVs on a typical distribution network in Blacksburg is investigated in [5]. The network consists of five homes and two PHEVs. Two charging strategies are considered: a) PHEVs are charging at 6 p.m. and b) all PHEVs charging at off-peak hours. The first strategy is the worst case scenario and results in high load on the network but still does not endanger the reliability of the system. They conclude that breakthrough of PHEVs imposes a new load on the distribution grid however; this load should be manageable with smart techniques such as Advanced Metering Infrastructure (AMI). Despite the interesting conclusion, their study is overly simplistic. It is not clear whether this hypothetical simulation represents the case of a large fleet of electric vehicles and their impact on distribution grid under uncontrolled charging.

Two cases of randomly and coordinated charging in the existing network is compared in [6]. They assume a direct coordinated charging will be done by sending signals to the individual vehicles. They conclude that coordinated charging of PHEVs can mitigate power loss and voltage deviation. However, when the choice of charging periods is arbitrary the impact of PHEVs penetration level is high. Also, the implementation of coordinated charging is not costless. 
The most fundamental principle regarding the power grids and their reliability revolves around the need to balance the demand and supply at every point in time because the change of frequency beyond a predetermined limit jeopardises system reliability and might create black outs. In the view of the fact that the current distribution network is not designed to deal with the load of electric vehicles, it is important to investigate this problem and the ways to implement an effective load management technique. If it remains unaddressed, this problem will result in congestion in the distribution networks, higher risks of outages and loss of quality of supply.

A possible solution to this problem might be provided by a smart grid, which adds monitoring, analysis, control, and digital communication capabilities to the power network to maximize the throughput of the system while automatically balance the supply and demand.

\section{Model assumptions}

Around 28.4 million vehicles have been registered in the UK during 1999-2008 [7]. From this amount $61 \%$ are commuting cars, $9 \%$ are company cars and $30 \%$ belongs to retired and unemployed people [7]. In the absence of information we assume that the same share applies to the electric vehicles. We group them into two different categories, vehicles used by employed people (commuting and company vehicles) and unemployed people with the share of $70 \%$ and $30 \%$, respectively. Furthermore, the future penetration of PHEVs in 2030 and under the Business as Usual (BAU) scenario will reach around $9 \%$ of the fleet whereas in the High Range (HR) scenario this amount increases to around $28 \%$ [8]. In our model, PHEVs' penetration is assumed to be $10 \%$.

The traffic pattern of PHEVs is assumed to be the same as conventional vehicles and constant for both groups throughout the week. Using the traffic data [8], the probability that a vehicle is travelling at each point in time can be computed by:

$P r_{t}=\left(\frac{\text { index of hour } t \text { in week days }}{\text { maximum index in weekdays }}\right) \times 0.7+\left(\frac{\text { index of hour } t \text { in saturday }}{\text { maximum index in saturday }}\right) \times 0.3$

where, $t$ ranges from 1 to $24 . P r_{t}$ gives the probability that vehicle is en route at each hour during the day. Likewise, the probability that a vehicle is parked at each time in the day can easily be calculated by $P r_{p t}=1-P r_{t}$. This result is presented in Figure 1(left).
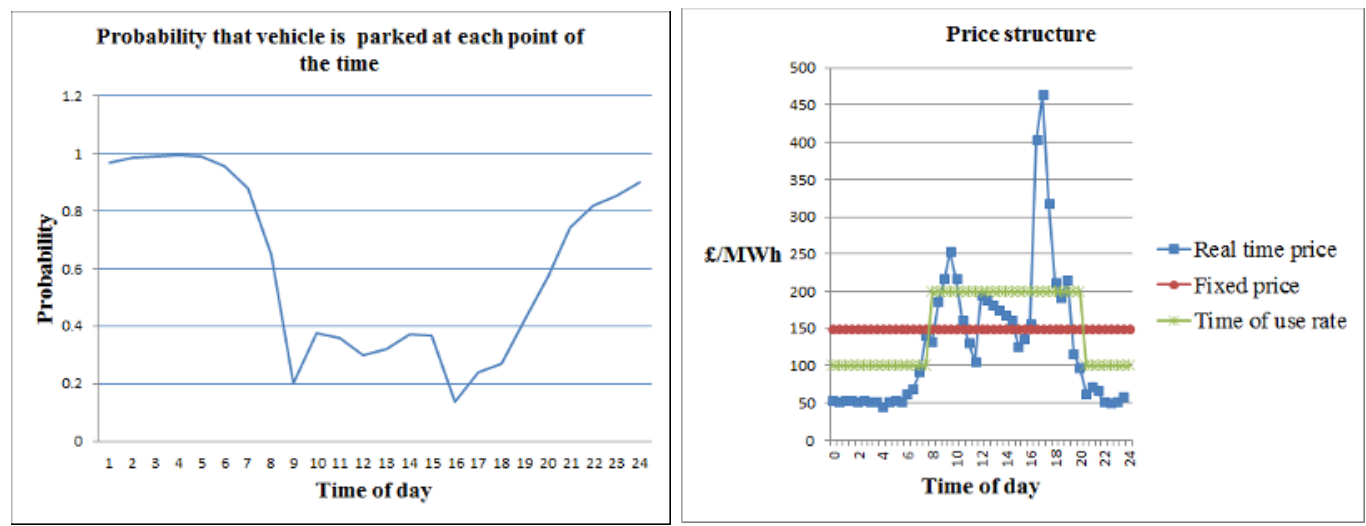

Fig.1 Being parked probability and price structure 
Price structure is assumed to be a key determinant of charging time. Figure1 (right) presents three different price structures that adopted in our model. These are: fixed price, time of use rate and real time pricing which corresponds to the uncontrolled, controlled off-peak and smart charging respectively.

\subsection{Current Grid-Uncontrolled charging}

The case of uncontrolled charging refers to the state that there is no way to incentivise consumers because the price is flat so the consumers are indifferent between different hours in the day. Thus, the most obvious charging time is when the vehicle arrives at home. Considering the working hours, we can safely assume that the home arriving time from work starts from 17:30 onward. Every half an hour a new group of vehicles is added to the network until 1:00 in the morning. The final plugging in time is selected to be 1:00 because it takes approximately 7 hours for the vehicle to be charged [9]. Moreover, the vehicles are assumed to be ready at 8:00 o'clock next morning.

Based on the being parked probability distribution (Figure 1), the load from the vehicle are calculated and added to the aggregate load profile using the following formula:

$V L_{t}=\left(P r_{p t}-P r_{p(t-1)}\right) \times n \times\left(\left(C a-S o C_{t}\right) / 1000\right)$

$V L_{t}:$ Load of vehicle at time $\mathrm{t}$

$\operatorname{Pr}_{p t}$ : Probability that vehicle is parked at time $\mathrm{t}$

$n$ : Total number of PHEVs based on $10 \%$ penetration

Ca: Battery capacity (Power-KW)

SoC : Initial state of battery when starts charging

As it can be seen from the formula (2), the load is divided by a factor of 1000 in order to be consistent with the aggregate load profile in terms of units (both in MW). Since in this scenario vehicles arrival time starts from 17:30 and ends at 1:00 o'clock, we have 16 groups of vehicles and 30 stages of load aggregation. Therefore, the total load including PHEVs' load in each stage, will be computed by the following algorithm.

Stage1 $V L_{1}+A L_{1}$

Stage2 $V L_{1}+V L_{2}+A L_{2}$

Stage14 $V L_{1}+V L_{2}+V L_{3}+\cdots V L_{14}+A L_{14}$

Stage15 $V L_{2}+V L_{3}+V L_{4}+\cdots V L_{14}+V L_{15}+A L_{15}$

Stage16 $V L_{3}+V L_{4}+V L_{5}+\cdots V L_{14}+V L_{15}+V L_{16}+A L_{16}$

Stage28 $V L_{14}+V L_{15}+V L_{16}+A L_{28}$

Stage29 $V L_{15}+V L_{16}+A L_{29}$ 
Stage30 $V L_{16}+A L_{30}$

Where $A L_{t}$ is aggregate load in period t (without presence of PHEVs). The initial state of charge $\left(S_{o} C_{t}\right)$ is assumed to be $30 \%$ of full capacity for the first group of vehicles arriving to the network and drops linearly thereafter. This assumption is based on the daily distance travelling of private cars [10]. Thus, we have:

$$
S o C_{t}=\frac{0.3 C a}{1-T}(t-T) \rightarrow S o C_{t}=\frac{1.247}{1-16}(t-16)
$$

In the case of uncontrolled charging $\mathrm{T}=16$ and $\mathrm{t}=1 \ldots 16$. On the other hand, the capacity ${ }^{2}$ of the battery used in the model is $29.09 \mathrm{KWh}$ and since it takes approximately 7 hours for the battery of vehicle to be charged, the power of battery will be $\mathrm{Ca}=4.156 \mathrm{KW}$.

\subsection{Current Grid-Controlled off peak charging}

In this scenario, the price structure is assumed to be time of use rate with peak hour from 8:00 in the morning to 20:00 in the evening. During peak hours, price doubles with respect to the off peak period, because it provides an incentive for the consumers to shift their demanded load to the off peak period. Under this price structure, consumers choose off peak periods for charging in order to save in cost of charging. Therefore, charging time starts from 20:00 in the evening until 1:00 o'clock in the morning. Using an algorithm similar to section 3.1, every half an hour one group of vehicles will be added to the network considering their probability of presence and initial state of their charge.

\subsection{Smart Grid Environment- Smart Charging}

In this scenario it is assumed that all vehicles receive wholesale market spot price on a semi- hourly basis and there is a two way communication between vehicles and the utility company. We use a similar algorithm to section 3.1 however; the loads are simulated based on the real time pricing. In order to simulate demand response in this case, it is assumed that the probability that a vehicle owner is willing to charge at the lowest price is $100 \%$. Hence, for the remaining prices, over 24 hours, the probability that an owner is willing to charge is calculated by:

$$
P r_{\text {sct-p }}=\frac{\text { Minimum price over } 24 \text { hours }}{\text { price in period } t}
$$

The probability that a vehicle is able and willing to charge $\left(P r_{s c t}\right)$ considering the price response $\left(P r_{s c t-p}\right)$ and vehicle availability $\left(P r_{p t}\right)$, at each point in time is computed by (5).

$$
P r_{s c t}=P r_{s c-p} \times P r_{p t}
$$

In the case of smart charging, the consumer will wait until the price falls. Thus, the charging starts from 22:00 in the evening during the winter. As in this hour the price is around 80\% lower than peak hour price, the consumer response seems to be quite rational. For the summer period, the charging time is 20:30. Like the previous scenarios, every half an hour a new group of vehicles will be added to the network until 1:00 o'clock in the morning. The load coming from those vehicles will be calculated by (6) where $P r_{s c t}$ is the probability a vehicle is able and willing to charge considering price.

$$
V L_{t}=\left(P r_{s c t}-P r_{s c(t-1)}\right) \times n \times\left(\left(C a-S o C_{t}\right) / 1000\right)
$$

\footnotetext{
${ }^{2}$ This capacity is the weighted average of three widely used models of batteries in the market.
} 


\section{Results and Discussion}

Figure 2 depicts the seasonal load profiles in the UK. They are used as the base case for each type of charging scenarios and the simulation results are added over these two seasonal load profiles. As it can be seen the shape of load profile for the summer and winter is almost similar however, electricity consumption in the UK is highly influenced by temperature hence; the demand is considerably higher in the winter compared to the summer.

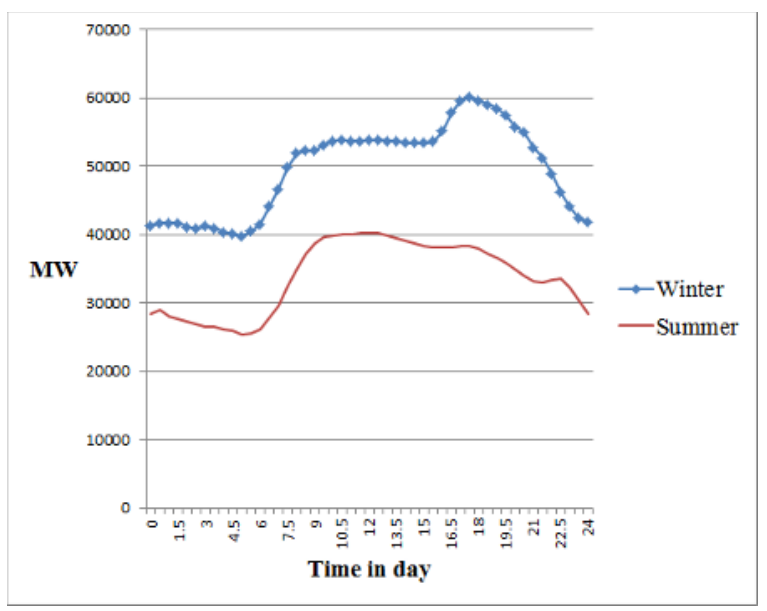

Fig. 2 Aggregate seasonal load profile-UK

\subsection{Uncontrolled charging scenario}

The case of uncontrolled charging is an extreme scenario which is assumed to happen under the fixed price structure. In this case, the consumer has no incentives to shift his or her demanded load. As it can be observed from figure 3, uncontrolled charging will result in a new peak in the off peak period. This case is of high concern, especially in the winter when the conventional peak demand reaches $60 \mathrm{GW}$ and the presence of PHEVs raises it by around $4.2 \%$. Conventional peak demand in the winter for the particular studied day happens around 17:30. The PHEVs increase duration of this peak demand with a considerable change in magnitude. Under these circumstances there is a great possibility of black out in some areas not only because of supply problems but also because of network inability to deliver such a huge amount of load.

In the studied summer day, however, without PHEVs there is no considerable peak like in winter. Demand increases from 8:00 in the morning to almost a constant amount of 40GW until 12:30 in the afternoon. Thereafter, it decreases slightly in each of the following hours until midnight. On the contrary, with PHEVs it can be observed that demand peaks up around 17:30 which lasts for around 5.5 hours (until 23:00). The new peak is $2.1 \%$ higher than the highest demand without PHEVs on that day. 


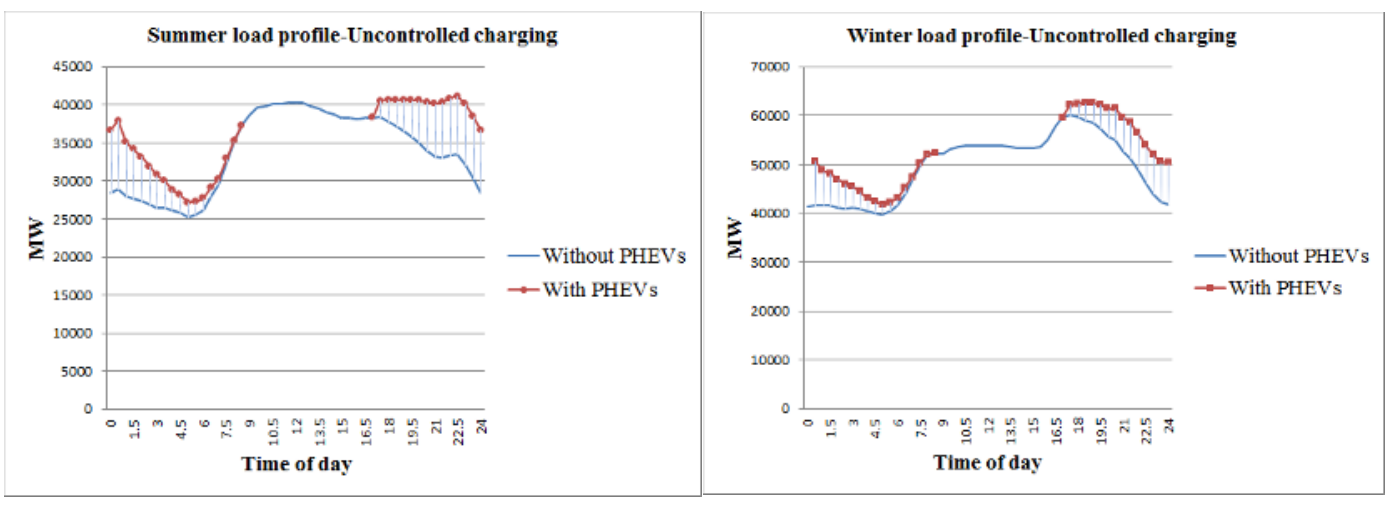

Fig.3 Load profile-Uncontrolled charging

\subsection{Controlled off peak charging scenario}

The case of controlled off peak charging is based on providing incentives for the consumers to shift their charging time to the off peak period. As it can be seen from figure 4, controlled off peak charging also creates a new peak in the late evening both during the summer and the winter. In the summer it creates a new peak at 20:00 which is around 3.7\% higher than the highest demand without PHEVs in that day. In this scenario, peak demand in the summer is around $41.82 \mathrm{GW}$, quite similar to uncontrolled charging in the same day but shorter in duration. This happens because the rest of the load is shifted to the off peak. During the winter, peak demand shifts from 17:30 to 20:30. Also, it is $2.1 \%$ higher than the base case scenario. In comparison with the case of uncontrolled charging, peak demand in the winter is not significantly lower; however, the duration of the peak is much lower. That is, excess capacity is still needed to satisfy peak demand even for a short period of time. This excessive peaking capacity has two side effects. First, there always should be sufficient power system to satisfy peak demand, otherwise there will be a black out. Second, when the consumers do not pay the price based on the actual cost of supply, those who consume less in peak hours subsidise the ones who consume more and this cross subsidy raises a regulatory issue.
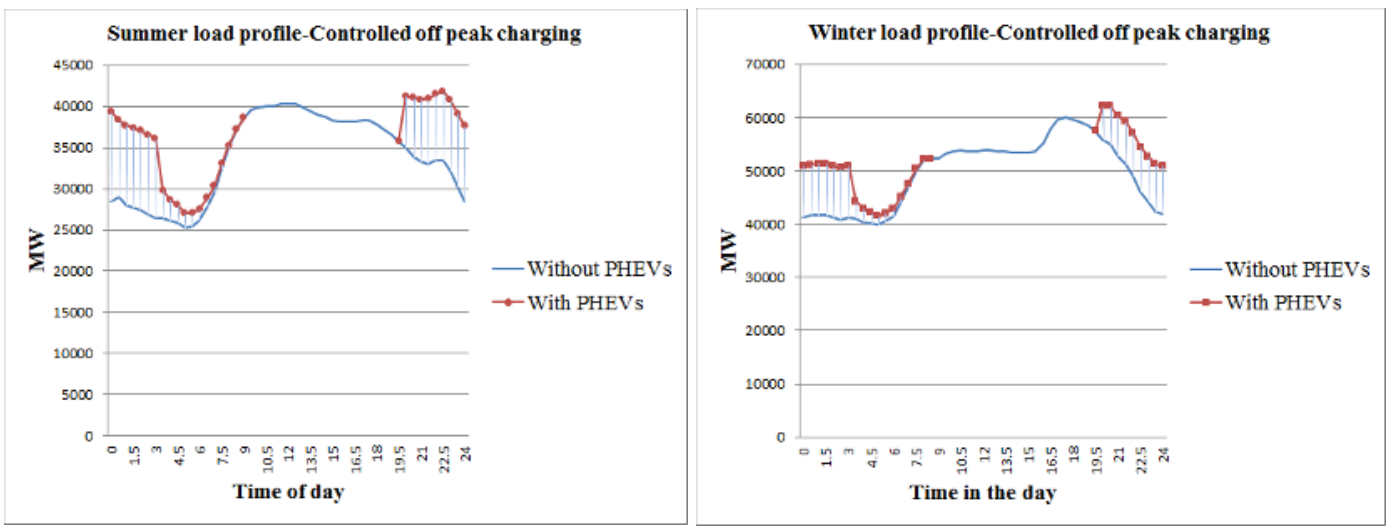

Fig.4 Load profile- Controlled off peak charging 


\subsection{Smart grid environment and real time pricing scenario}

In this section we consider the final scenario, which is based on the smart charging in a smart grid environment. In the winter, which is always the worst case scenario, the highest total load including PHEVs is around $4.6 \%$ less than the existing peak demand without PHEVs (see figure 5). This means that in the smart grid environment, peak load will not increase further with PHEVs although the same amount of load as in the normal grid is being placed. A similar result is obtained in the case of summer, when new load (including PHEVs) in the highest point is less than peak demand without PHEVs.

Perhaps, along with the benefits from the generation point of view, the main advantage in the consumer's eye is the decrease in cost of charging. These cost savings result from the fact that a big chunk of PHEVs' load has shifted to the period of lowest demand and consequently lowest price. The other positive consequence of the smart grids is that it minimizes the impact of extra peak demand load on the wholesale electricity price. This is exactly opposite the case of fixed rate that everyone has to pay the price for the added burden on the grid, even those who do not use PHEVs.
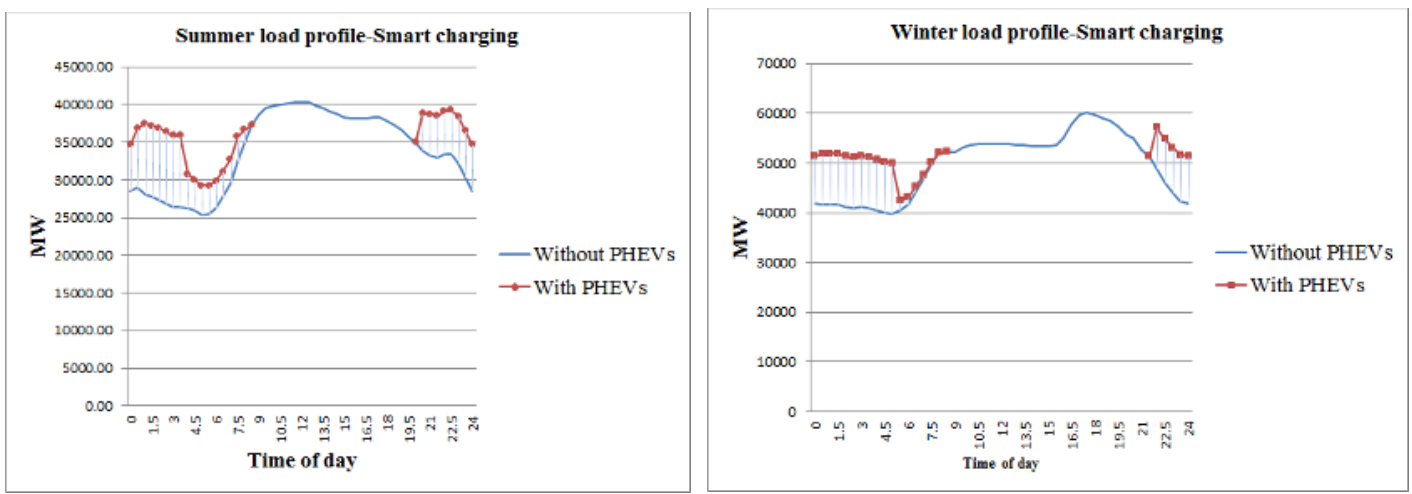

Fig.5 Load profile-Smart charging

\subsection{Impact of different price structures on load distribution}

Figure 6 illustrates the load distribution of PHEVs under three different scenarios. As it is evident from the graphs, in the case of uncontrolled charging, the load imposed on the network is mainly concentrated on high demand hours (i.e. 17:30 to 24:00, right graph). For the case of controlled off peak charging the PHEVs' load is almost distributed evenly between high demand and low demand hours (i.e. 24:00 to 8:00, middle graph). By contrast, in the smart grid environment the main part of the PHEVs' load has shifted to the period of low demand (left graph).
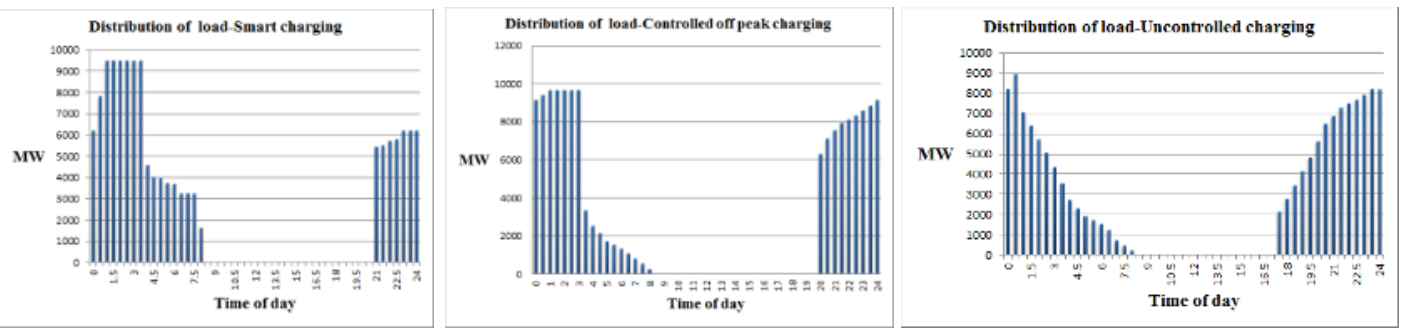

Fig.6 Comparison between PHEVs load distribution under three different scenarios 


\section{Conclusion}

Strict environmental regulations and EU targets aimed at decreasing the level of $\mathrm{CO} 2$ emissions have placed the electrification of the transport system at the centre of policy makers' attention. However, it gives rise to the new challenges regarding the possible impact of PHEVs' penetration on power system stability. The problem is not only possible supply problems, but also within the network itself, which might not be able to deliver the needed power to some areas.

The results show that the current grid might be unable to deal with the increasing load of PHEVs. Under the fixed price and time of use rate, a new peak will emerge in the late evening and this peak in many cases is higher than the existing peak without PHEVs. Therefore, there is a great possibility of congestion in the network, loss of voltage and frequency, and ultimately black outs. A similar situation holds for the controlled off peak charging under time of use rate. In comparison with uncontrolled charging, time of use rate does not provide a lower peak demand and it only decreases the duration of peak. These results suggest that even controlled off peak charging has a limited capacity and cannot be accounted as a comprehensive solution to the problem of PHEVs' load.

However, the simulation results show that real time pricing in the smart grid environment will not deteriorate the current peak demand. Instead, the smart grid effectively distributes the demand over the off peak period. In winter, when the system reliability concerns increase, it can be seen that no new peak emerges. Similarly, in the summer the maximum demand including PHEVs is lower than the existing peak demand without PHEVs. Therefore, by the aid of demand response in the smart grid environment, accommodating a huge number of PHEVs becomes technically and economically feasible.

\section{References}

1. European commission homepage, EU targets for sustainable growth, (available online) http://ec.europa.eu/europe2020/priorities/sustainable-growth/index_en.htm. Date assessed: 1507-2011

2. A.Y, Saber, G.K, Venayagamoorthly :Plug-in vehicles and renewable energy source for cost and emission reductions IEE Transaction on Industrial Electronics, Vol. 58, No. 4, pp. 12291238(2011).

3. W.Shireen, and S.Patel,: Plug-in Hybrid Electric vehicles in the smart grid environment Transmission and Distribution Conference and Exposition, IEEE PES, pp. 1-4 (2010)

4. R.C, Green, L.Wang, M. Alam, : The impact of plug-in hybrid electric vehicles on distribution networks: a review and outlook, Renewable and Sustainable Energy Reviews, vol. 15, no. 1, pp. 544-553(2011)

5. S.Shao, M. Pipattanasomporn, S.Rahman, : Challenges of PHEV penetration to the residential distribution network, IEEE PES General Meeting, paper 09GM0514, pp. 1-8. (2009)

6. K.Clement-Nyns, E.Haesen, J. Driesen,: The Impact of charging plug-in hybrid electric vehicles on a residential distribution grid" IEEE Transactions on Power Systems, Vol. 25, No. 1, pp. 371-380 (2010) .

7. Travel Survey statistical release, Department for Transport (DfT)- (available online) http://www2.dft.gov.uk/pgr/statistics/datatablespublications(2009). date accessed 08-07-2011

8. Travel Survey statistical release, Department for Transport (DfT)-(available on line) http://www2.dft.gov.uk/pgr/statistics/datatablespublications (2008) - date accessed 08-07-2011

9. K.Qian, , C.Zhou, C. Allan. M., Y.Yuan, :Load Model for Prediction of Electric Vehicle Charging Demand: International conference on Power System Technology IEEE pp.1-6 (2010)

10. Travel Survey statistical release, Department for Transport (DfT)-(available online) http://www2.dft.gov.uk/pgr/statistics/datatablespublications (2007) - date accessed 08-07-2011 